\title{
A Day in the Life of Yeeranna - A Cautionary Tale
}

\author{
T. F. DAVEY \\ LEPRA, Fairfax House, Causton Road, Colchester, CO1 1 PU, U.K.
}

\begin{abstract}
Considering the clinical and bacteriological data of a known untreated patient with early lepromatous leprosy in the setting of personal habits, social behaviour, insect transmission and modern transport, it becomes possible to envisage an ordinary day in the life of this patient in which he becomes the source from which 100 people are infected with Mycobacterium leprae up to a distance of 50 miles from his home. In 1 month this total could become 3000 , and if only $1 \%$ of these developed clinical leprosy, 30 cases of leprosy would result, of whom possibly 3 could be potentially lepromatous in type.
\end{abstract}

\section{Background}

It seems to be a common characteristic of our human condition that whereas new truth may be accepted in the abstract, its application in practical planning and behaviour is a different matter and may involve a long time-lag, especially where long established tradition or cherished religious ideas are concerned.

Leprosy is no exception to this. During recent years various strands of evidence have been accumulating regarding the mechanism of transmission in leprosy which taken together expose the inadequacy of traditional ideas and procedures, but are not as yet being given the importance they merit in current leprosy control programmes. It is worth summarizing them here.

Pedley $(1970,1973 a, 1973 b)$ demonstrated the unimportance of the unbroken skin surface in lepromatous leprosy in contrast with the nasal discharge as a source of acid-fast bacilli (AFB). Davey and Rees (1973, 1974), in a substantial series, showed (a) that a nasal discharge laden with AFB was consistent with very early clinical lepromatous leprosy; (b) that the AFB were undoubtedly Mycobacterium leprae; (c) that huge numbers of viable $M$. leprae could be involved (mean 18.59 millions in 17 early morning specimens, 30.72 millions in 1424 -h specimens); (d) that $M$. leprae could remain viable outside the body for 2, and in 1 case for 7, days. Desikan (1977) showed that this period could be extended to 9 days. Pedley (1973b), and Davey and Rees (1974) agree in emphasizing the association of a bacilliferous nasal discharge 
with the lepromatous form of the disease. Davey (1974) mentioned the frequency with which patients need to clear their noses as related to atmospheric humidity. In fact, while 5 or 6 times daily may be needed in humid conditions, once or twice may suffice in dry weather.

Geater (1975) in well controlled experiments demonstrated that some of the commonest varieties of domestic flies, Musca, Stomoxys and Calliphora could transfer AFB including globi (powerful evidence that the AFB were M. leprae), from infected nasal discharge to uninf ected surfaces via their gut, mouthparts, abdomen and legs, and some were still capable of doing this $24 \mathrm{~h}$ after feeding on the infected material. (These flies are positively attracted to any defect of skin surface, and have a range in the case of Musca of 2 miles, in the case of Calliphora of 5 miles.) Rees (1975) commented on the importance of these findings.

The uncleanly nocturnal habits of cockroaches (Blatta orientalis) are well known and are exploited in the story which follows. These and several other biting insects are implicated in the carriage via their gut of viable $M$. leprae from the blood of lepromatous patients to other surfaces. Narayanan, Shankara Manja et al. (1972) obtained multiplication in mice typical of $\boldsymbol{M}$. leprae from material obtained from 2 Culex mosquito pools. Sengupta, Worms and Rees (1976) showed that viable M. lepraemurium could be carried by Aedes aegypti.

Finally, Rees and McDougall (1977) found experimental evidence for the development of $M$. leprae infection in mice following the inhalation of aerosols containing the bacillus. This important finding opens up the possibility that infected house dust may be a potential source of leprosy infection.

None of these findings has been disputed. Their implications can be fully appreciated only when they are brought together and related to the actual mode of life of large numbers of people in areas of the world where leprosy is endemic today. It is easy for the scientist to be isolated by his own social background from the detailed facts of daily living experienced by the poor. The truth is that in a setting of poverty, people who are naturally clean in themselves cannot afford the standards of housing, sanitary and washing facilities, handkerchiefs and tissues taken for granted in affluent societies. When to this is added the assault on personal dignity which leprosy creates, a picture is produced of the potential for transmission of the disease by the lepromatous patient which merits much food for thought. Let us consider a typical example.

\section{The Patient}

Yeeranna is a real person, though that is not his actual name. Aged 20, he presented himself one January morning at the out-patient department of a leprosy referral hospital in a large Asian country. He gave a history of a pale patch on the right thigh which had been there for $1 \frac{1}{2}$ years. Three months before coming to hospital he had experienced what was thought to be influenza, following which very numerous erythematous new patches had appeared and were still multiplying, combined with abnormalities of sensation in his legs. At the same time he had become aware of slight but definite 
changes in his facial appearance, not obvious as yet to the casual observer, but plain enough when he looked at himself in a mirror, and especially involving his ears, forehead and nose. For the past month his nose had become increasingly blocked by catarrh, which he needed to clear 5 or 6 times a day when the weather was damp, but which caused hard crusting under dry conditions. He did not volunteer this information about his nose, but responded to direct questioning. He had taken no treatment, as up to this point he could not face the possibility that this was leprosy, and had indeed come secretly to hospital without the knowledge of his family.

Clinically he was suffering from very early lepromatous leprosy, a degeneration from an earlier borderline type. The diagnosis was confirmed histologically and routine smears for M. leprae were strongly positive (BI 5.5, MI 5). The nasal discharge was typical, showing both globi in all stages of development and individual AFB, many of them elongate with active ingestion by macrophages. Internally his nose showed severe lepromatous changes, with nodulation and erosion of both inferior turbinates and a lepromatous plaque on the left septum. Smears from these areas were very strongly positive, BI 6 plus, MI 5-10. The patient was willing to stay in hospital for a while and willingly participated in a $24 \mathrm{~h}$ study of the nasal discharge. A $24 \mathrm{~h}$ specimen flown to Dr Rees's laboratory in London gave $24 \mathrm{~h}$ later a total count of $1.5 \times 10^{9} \mathrm{M}$. leprae, with $5 \%$ viable.

Thus, on the day he provided the specimen at least 75 million viable $M$. leprae had left the body of this patient by the nasal route alone. Although the clinical condition of the patient was typical of many others, this happened to be the highest count among the 31 in the series examined in London, so for the purposes of the story which follows it has been reduced to the mean for the whole series of 24-h nose blows, namely 30 millions of viable $M$. leprae in the $24 \mathrm{~h}$.

It is intriguing to consider what was happening to the bacilli discharged from the nose of this and other similar patients during the days prior to their coming to hospital. Knowing the conditions in which many of them live, it requires no great flight of the imagination to project the findings enumerated above into the life of this patient, and picture what could easily have taken place on the day before he left his home for the hospital. This is attempted in the story which follows.

\section{One Day in the Life of Yeeranna}

At 5 a.m. Yeeranna awoke as usual. This was not his first awaking since going to bed. Restless with anxiety and the discomfort of a blocked nose, he had felt at 2 a.m. that he simply must clear his nose. Not wishing to disturb other members of his family by going outside, he had in fact in his half sleepy condition cleared his nose by his bedside in a corner of the room.

The discharge contained 3 million viable $M$. leprae, and during the night was visited by 10 cockroaches, the feet, abdomens and mouth-parts of which became grossly contaminated. After feeding the insects walked about the room depositing bacilli as they did so. One crossed the legs of Yeeranna's little son 
and deposited 10,000 M. leprae on a small scabetic lesion on his leg. Six of the insects had come from adjacent lodgings to right and left of Yeeranna's own, and deposited their quota of bacilli there. This pattern of events had been going on for 2 weeks, and with bacilli remaining viable for several days, the dust in all 3 lodgings was by now liberally impregnated with living $M$. leprae, contact with which was inevitable for all the occupants.

Round about 5 a.m. Yeeranna went outside for his morning ablutions. He needed to clear his nose and did this on the ground nearby. During the morning, before the heat of the day dried it up, the discharge was visited by 20 domestic flies of the genus Musca, all of which became contaminated by large numbers of AFB from the 5 million contained in the discharge. These flies scattered in all directions, and within $1 \mathrm{~h}$ had deposited significant numbers of $M$. leprae on cuts, abrasions and ulcers on the skin of 25 persons.

At 10 a.m. Yeeranna walked through the town. It was market day and by 11 a.m. the market was crowded. Once again he felt the need to clear his nose, and another 3 million viable $M$. leprae were deposited on the ground. This time the flies attracted included the powerful and far ranging Calliphora, and within $1 \mathrm{~h}$ the skins of 30 people were contaminated by $M$. leprae, including $10 \mathrm{from}$ parts of the town over 1 mile away and 5 from adjacent villages. A new factor on this occasion promoted even wider dispersal of bacilli when 3 people one after another trod in the discharge and carried substantial numbers of bacilli away on the side of their sandals. Two of these had come from villages 3 and 6 miles away. In both cases there were still 100,000 viable bacilli still adherent to their sandals when they arrived home by ox cart some hours later, and the local flies were able to disseminate them in a fresh locality.

At 3 p.m. Yeeranna went to the local bus station to meet his brother and family who were returning home on a visit to their parents. Once again Yeeranna felt the need to clear his nose and did this outside the gentlemen's convenience, discharging another 5 million bacilli. Once again flies, both Musca and Calliphora were attracted, and this time transported viable $M$. leprae to a nearby school so that 20 children received more than sufficient to initiate infection. Once again passers by trod in the discharge, and all 5 who did this happened to be travelling by bus to villages 10, 2030,40 and 50 miles away, carrying substantial numbers of $M$. leprae with them.

The final nose clearance of the day took place at around 7 p.m. outside Yeeranna's house. Although flies were by now not very active, many people were still passing by, and 5 persons who trod in the discharge transported a total of 500,000 viable bacilli on the sides of their feet to their homes in various parts of the town, where a fresh series of contacts became possible.

Thus at the end of the day, Yeeranna had been responsible for providing more than sufficient viable $M$. leprae to infect at least 100 people up to a distance of 50 miles from his home.

\section{Discussion}

This is a story with a moral, not a record of scientific experiment. The sequence of events described is incapable of investigation in detail and 
confirmation by a microbiologist. What can be said is that not a single element in the story is out of line with observed facts whether in the spheres of microbiology, entomology or sociology. These events could have taken place. Repeated daily for 1 month they could mean that this 1 patient with untreated early lepromatous leprosy could have been responsible for the transmission of significant numbers of viable $M$. leprae to 3000 people within a radius of 50 miles from his home. Very few of these would be likely to develop overt clinical leprosy, but even if the number who did was $1 \%$ of the total, there would be here 30 cases of clinical leprosy, of whom possibly 2 or 3 would be lepromatous.

Once we have accepted that vectors such as flies may transport viable $M$. leprae and that nowadays public transport facilities are widely used, 2 obvious conclusions follow. One is the inadequacy of traditional concepts which try to trace fresh infections to some existing leprosy patient who lives in the close vicinity, and if this person happens for example to have Indeterminate, $\mathrm{BT}$ or BB leprosy, conclude that non-lepromatous leprosy is a significant source of new infections.

The second point is the uniqueness of the untreated lepromatous patient as a source of inf ection to other people by virtue of the bacilliferous nasal discharge which is limited to this type of leprosy, may coincide with very early clinical disease, and indeed may be present at the point when a borderline type of the disease is degenerating into the lepromatous type even before the change is clinically obvious. Quite clearly, high priority needs to be given in all leprosy control programmes to the search for and treatment of every person with overt or potential lepromatous leprosy.

Nothing was said in the story regarding bacillaemia and the carriage of $M$. leprae by biting insects, the reason being that although evidence is mounting that here is another route of transmission, obviously applicable to Yeeranna's case, its importance is not yet determined. Nevertheless, here is another pointer to the unique importance of the untreated person with lepromatous leprosy in spreading the disease.

Finally we can no longer think of leprosy eradication in isolation from the wider issues of personal hygiene and insect control. Our colleagues in tuberculosis control learned this lesson a long time ago.

\section{References}

Davey, T. F. and Rees, R. J. W. (1973). The nasal discharge in leprosy. Abstracts of 10th International Leprosy Congress, Bergen, p. 30.

Davey, T. F. and Rees, R. J. W. (1974). The nasal discharge in leprosy: clinical and bacteriological aspects. Lepr. Rev. 45, 121.

Davey, T. F. (1974). The nose in leprosy: steps to a better understanding. (Editorial) Lepr. Rev. $45,97$.

Desikan, K. V. (1977). Viability of Mycobacterium leprae outside the human body. Lepr. Rev. 48, 231.

Geater, J. G. (1975). The fly as a potential vector in the transmission of leprosy. Lepr. Rev. 46, 279.

Narayanan, E., Shankara Manja, K., Kirchheimer, W. F. and Balasubrahmanyan, M. (1972). Occurrence of Mycobacterium leprae in Arthropods. Lepr. Rev. 43, 194. 
Pedley, J. C. (1970). Composite skin smears. Lepr. Rev. 41, 31.

Pedley, J. C. (1973a). The nasal mucus in leprosy. Lepr. Rev. 44, 33.

Pedley, J. C. (1973b). The nasal mucus in leprosy. Abstracts of 10th International Leprosy Congress, Bergen, p. 29.

Rees, R. J. W. (1975). Do flies transmit leprosy? (Editorial) Lepr. Rev.46, 255.

Rees, R. J. W. and McDougall, A. C. (1977). Airborne inf ection with Mycobacterium leprae in mice. J.Med.Microbiol. 10,63.

Sengupta, U., Worms, M. J. and Rees, R. J. W. (1976). Investigations of the mosquito as a possible vector in the transmission of human leprosy using $M$. lepraemurium as a model. Lepr. in India 48, No. 4 Supplement, 504. 